\title{
Experimental Investigation of the Shear Behavior of a Concrete Beam without Web Reinforcements Using External Vertical Prestressing Rebars
}

\author{
Xingwei Xue $\mathbb{i}$, Xuan Wang, Xudong Hua $\mathbb{D}^{D}$, Meizhong Wu, Longqing Wu, Zhuang Ma, \\ and Junlong Zhou
}

School of Traffic Engineering, Shenyang Jianzhu University, Shenyang, Liaoning 110168, China

Correspondence should be addressed to Junlong Zhou; 13889341820@163.com

Received 28 March 2019; Revised 4 June 2019; Accepted 13 June 2019; Published 23 June 2019

Academic Editor: Carlos Chastre

Copyright (C) 2019 Xingwei Xue et al. This is an open access article distributed under the Creative Commons Attribution License, which permits unrestricted use, distribution, and reproduction in any medium, provided the original work is properly cited.

\begin{abstract}
The shear performance of concrete beams is known to be an important mechanical feature; hence, enhanced shear resistance is critical for determining a beam's performance in terms of security and service life. This paper presents a study on the shear behavior of concrete beams without web reinforcement strengthened by external vertical prestressing rebars (EVPRs). Experimental data were obtained from seven test beams with varying influencing factors (stirrup ratio $\rho_{\mathrm{sEP}}$, arrangement spacing $s$, prestressing force $F_{\mathrm{p}}$, and compressive stress degree $\gamma_{\mathrm{p}}$ of the EVPRs) to determine their effects on the shear behavior. The results reveal that the EVPRs can significantly improve the shear capacity and ductility of concrete beams without web reinforcement. Furthermore, the failure mode is changed from brittle diagonal tension to relatively ductile shear compression, and the flexural cracks and shear cracks are more fully developed. The shear capacity becomes enhanced as the $\rho_{\mathrm{sEP}}$ and $\gamma_{\mathrm{p}}$ are increased; vertical compressive stress provided by the EVPRs can reduce the principal tensile stress of the concrete structure to prevent the shear cracking and enhance the shear resistance of the concrete. Meanwhile, in the stage from the formation of the critical shear crack (CSC) to the shear failure, the EVPRs can be used as stirrups to share the shear load. It can be concluded that EVPRs can effectively improve the shear performance of concrete beams.
\end{abstract}

\section{Introduction}

Shear capacity is one of the most important parts of RC beams in structural design, although it occurs suddenly and may lead to catastrophic consequences, so RC beams should have sufficient shear capacity. However, in some cases, the failure of beams can take place due to a deficiency in the shear design. Research on enhancing the shear resistance mainly includes using ultrahigh-performance concrete $[1,2]$, fiber concrete [3-6], external bonding of steel or FRP plates [7-12], internal vertical prestressing rebars (IVPRs) [13-16], and external vertical prestressing rebars (EVPRs), which have been studied in depth by many researchers [17-21].

Vertical compressive stress, which is provided by vertical prestressing rebars arranged in the webs of a girder, is an active and effective approach for improving crack and shear resistance by reducing the principal tensile stress of the webs [22]. IVPRs as a means of providing vertical compressive stress were widely used in almost all the large-span concrete box girders. However, during the service life, cracks have still occurred in large quantities in IVPR girders [14, 23-29]. The shortcomings of conventional IVPR techniques are mainly summarized as follows: (1) the reserved holes of the vertical prestressing rebars weaken the effective area of the web and cause stress concentration; (2) because the reserved pores are narrow, they often cause segregation and bleeding in the grout, resulting in insufficient filling of the reserved pores; (3) it is difficult to effectively control and monitor the tensile force of EVPRs during tensioning and service; therefore, it is difficult to assess the enhancement effect of the shear capacity; and (4) since the pipelines have been grouted, IVPRs are difficult to replace. In order to solve the shortcomings of 
traditional IVPR techniques, EVPRs, the technique of arranging vertical prestressing rebars outside the web, have been proposed and studied.

The structure of EVPR was first proposed and studied in 1991 by Aboutaha and Burns [17] in terms of the behavior of retrofitted prestressed composite beams that originally lacked shear reinforcement. EVPRs can be successfully used to improve the shear strength of prestressed concrete composite flexural members that lack shear reinforcement, and the mode of failure of a prestressed composite flexural member could be changed from a sudden shear failure to a ductile flexural failure. Meanwhile, in 2003, Altin et al. [18] completed a shear test of $13 \mathrm{~T}$ cross-sectional beams. The experimental results showed that the EVPR is effective and that the specimens' strength, rigidity, and ductility were improved. EVPRs controlled any shear cracks and also helped to improve the ductile flexural behavior of the members.

In 2006, the results on the strengthening methods were presented [19], including on steel brackets, steel plates (with or without anchors), vertical steel strips, and EVPRs, which all can improve the ultimate shear strength of reinforced concrete beams and change the failure mode from brittle shear to flexural; but the EVPRs is the most effective method for shear strengthening of reinforced concrete beams. Accordingly, EVPR techniques deserve more research studies.

Based on the test data of 14 rectangular beams with EVPRs, Shamsai et al. [20] found that the test beams all suffered flexural failure, and some of the test beams did not crack in the critical shear region before failure. Test results have shown that the vertical compressive stress is taken as 0.04 times the concrete strength, which can effectively prevent the member from diagonal cracking. Thereafter, Demir et al. [21] completed the shear test of two series of beams. One series of beams were concrete beams without web reinforcements, and the shear strength of the beam enhanced by EVPRs was 2.11 times that of the beam without EVPRs. For the series of concrete beams with embedded web reinforcements, the shear strengths of the EVPR beams whose failure mode is shear failure and flexural failure were 1.6-1.82 times those of the control beam.

However, there are limited studies on the mechanisms of the EVPR technique. Specifically, there are virtually no related in-depth studies of the effects of EVPRs on a concrete beam with varying stirrup ratios and vertical compressive stress degrees of the EVPRs. Although the performance of a concrete beam with EVPRs is effective, the reasonable configuration of EVPRs can further improve this performance.

The aim of this study is to explore the effect of the EVPRs on the shear behavior of concrete beams without web reinforcement. The seven test beams include two concrete beams without web reinforcement as control beams and five concrete beams without web reinforcement enhanced by the EVPRs; a total of 7 beams are measured in this study. The shear behavior of beams with EVPRs was investigated, including the failure mode, shear capacity, ductility, cracks, and strain of the prestressing rebars with varying stirrup ratios, arrangement spacing, prestressing force, and vertical compressive stress degrees of the EVPRs.

\section{Experimental Program}

2.1. Vertical Compressive Stress Degree $\gamma_{p}$. After the EVPR is tensed, a tensile force is generated in the EVPR, which in turn generates vertical compressive stress on the beam through the anchoring beam (Figure 1). The vertical compressive stress can reduce the principal tensile stress of the beam, effectively putting off the generation of diagonal cracks, and achieve the purpose of enhancing the shear resistance of the concrete beam.

Two cases are used to discuss the stress state of the beams.

Case I. Consider a concrete beam without web reinforcements, whose height and width are $h$ and $b$, respectively. Under the action of the shear force $V$ (Figure 2(a)) at the beam height $h / 2$, unit A is only subjected to the shear stress $\tau$ (Figure 2(b)), and its magnitude is equal to the principal tensile stress $\sigma_{1}$ (Figure 2(c)).

At the moment of the formation of the diagonal crack, the shear stress $\tau$ is recorded as $\tau_{\text {cr }}$ and the principal tensile stress is recorded as $\sigma_{1 \mathrm{cr}}$. According to the first strength theory of material mechanics (maximum tensile stress theory), the standard value of uniaxial tensile strength of concrete $f_{\mathrm{t}}$ can be obtained for a beam:

$$
\sigma_{1 \mathrm{cr}}=\tau_{\mathrm{cr}}=f_{\mathrm{t}} .
$$

Case II. Applying EVPRs to the beam, which is in a critical state of diagonal cracking, can decrease the principal tensile stress $\sigma_{1 \mathrm{p}}$ (Figure 3(c)).

It should be noted that the shear stress of the section is only related to the shear force $V$ (Figure 3(a)) and the beam section size, regardless of whether the EVPRs are configured or not. Therefore, the shear stress of the EVPR beam can be assumed to be the same as the shear stress of the original structure, meaning that the shear stress of the beam with the EVPRs at the time of diagonal cracking is still $\tau_{\mathrm{cr}}$ (Figure 3(b)). That is,

$$
\sigma_{1 \mathrm{p}}<\tau_{\mathrm{cr}}, \quad\left(\tau_{\mathrm{cr}}=f_{\mathrm{t}}\right)
$$

Since the principal tensile stress $\sigma_{1 \mathrm{p}}$ is smaller than the standard value of the uniaxial tensile strength of concrete $f_{t}$, the beam is changed to an uncracked state and the purpose of reinforcement is achieved. The EVPRs are arranged according to the arrangement spacing $s_{\mathrm{p}}$. Two vertical prestressing steel bars are arranged symmetrically on both sides of the beam, and two pretensioning forces $F_{\mathrm{p}}$ act on the single vertical prestressing steel bar, as shown in Figure 1.

For unit A subjected to the vertical compressive stress $\sigma_{\text {zp }}$ and the shear stress $\tau$, the calculation formula of the principal tensile stress $\sigma_{1}$ is

$$
\sigma_{1}=-\frac{\sigma_{\mathrm{zp}}}{2}+\frac{1}{2} \sqrt{\sigma_{\mathrm{zp}}^{2}+4 \tau^{2}}
$$

Therefore, under the action of vertical compressive stress, the force conditions of unit A in the critical state of diagonal cracking are as follows: the shear stress is $\tau_{\mathrm{cr}}$ and is 


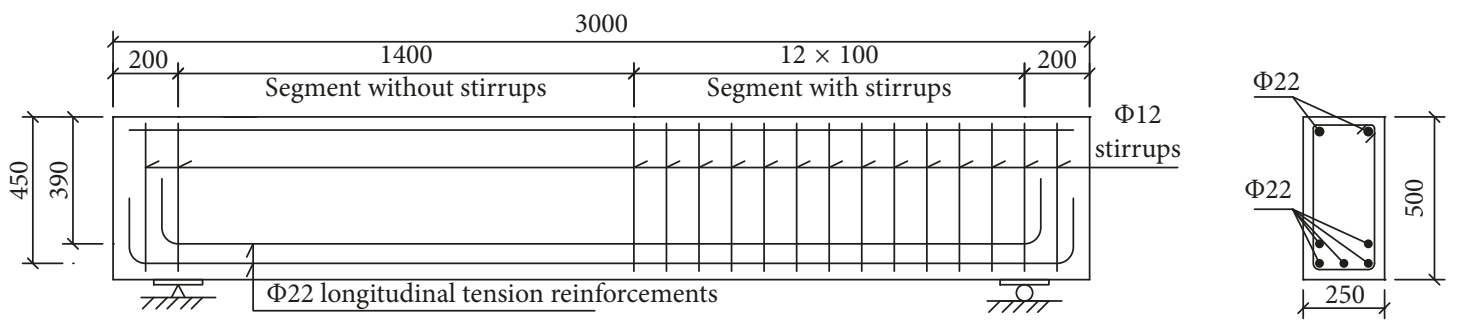

(a)
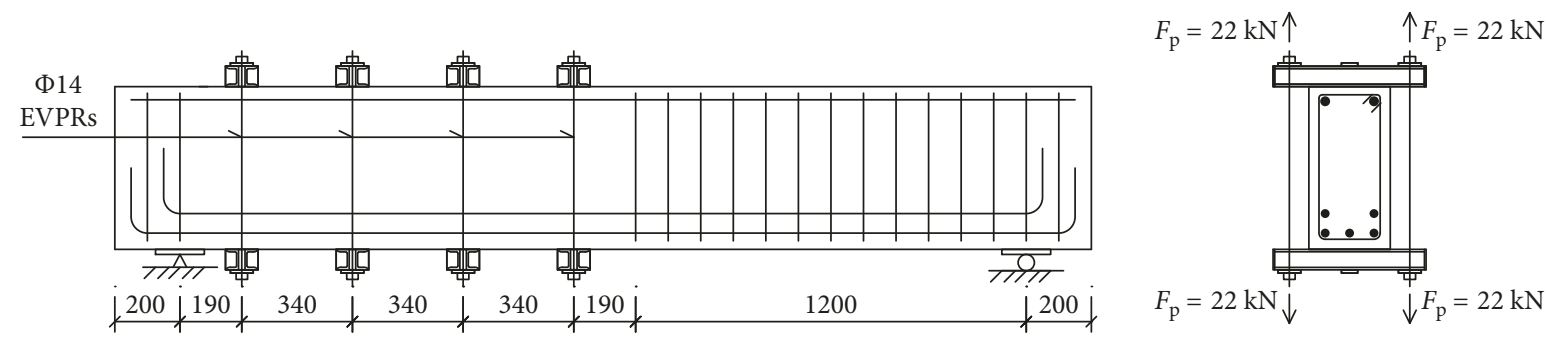

(b)
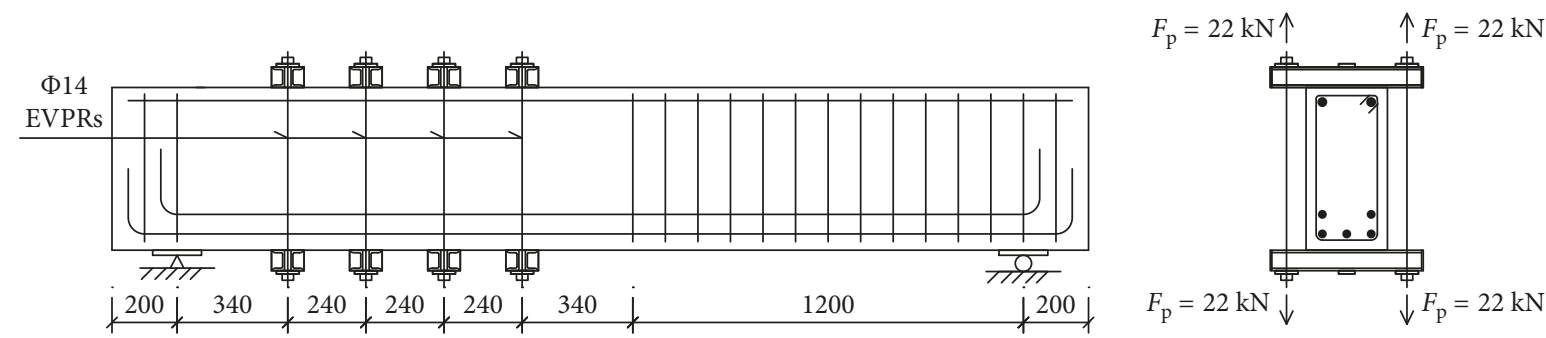

(c)
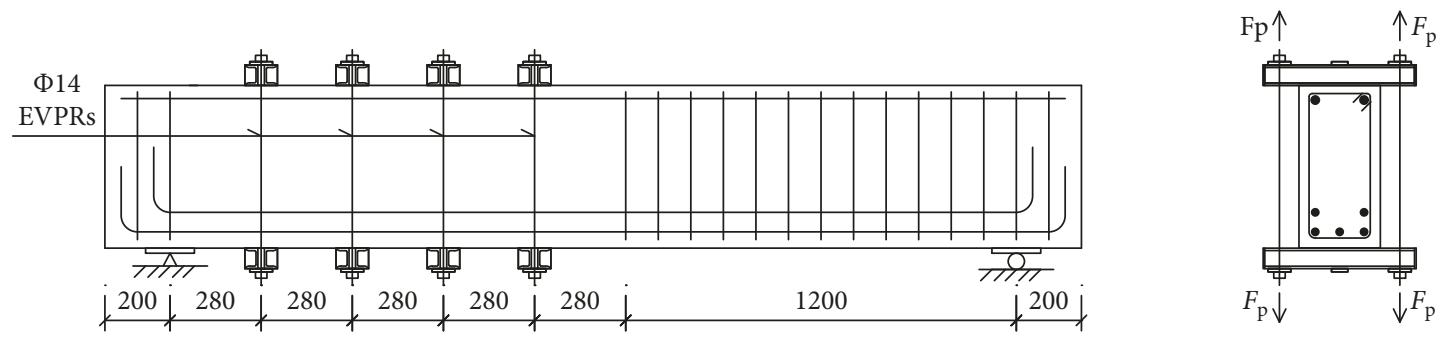

EP_P22_S3: $F_{\mathrm{p}}=22 \mathrm{kN}$ EP_P26_S3: $F_{\mathrm{p}}=26 \mathrm{kN}$ EP_P18_S3: $F_{\mathrm{p}}=18 \mathrm{kN}$

(d)

FIGURE 1: Geometric properties and reinforcement layout of the specimens (unit: mm). (a) RC_1, RC_2. (b) EP_P22_S1. (c) EP_P22_S2. (d) EP_P22_S3, EP_P26_S3, EP_P18_S3.

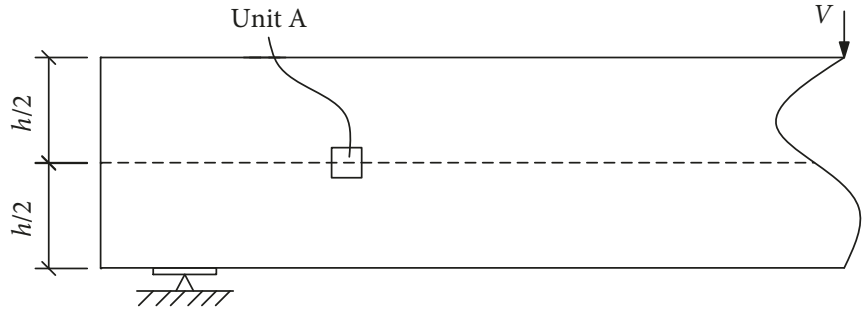

(a)

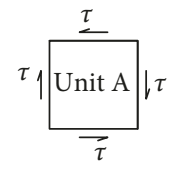

(b)

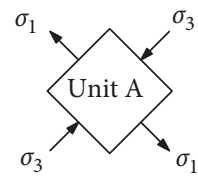

(c)

Figure 2: Stress analysis of unit A of RC members. 


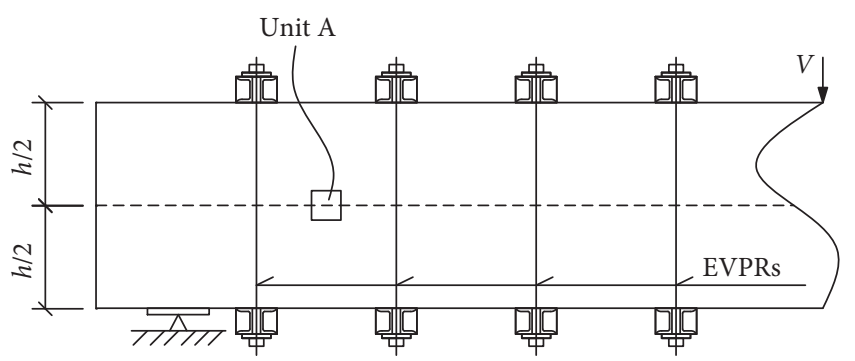

(a)

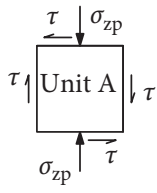

(b)

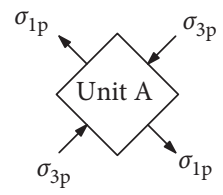

(c)

FIgURE 3: Stress analysis of unit A of EVPR members.

equal to $f_{\mathrm{t}}$ as analyzed by the previous process; then, the principal tensile stress $\sigma_{1 \mathrm{p}}$ is

$$
\begin{aligned}
& \sigma_{1 \mathrm{p}}=-\frac{\sigma_{\mathrm{zp}}}{2}+\frac{1}{2} \sqrt{\sigma_{\mathrm{zp}}^{2}+4 f_{\mathrm{t}}^{2}}, \\
& \sigma_{\mathrm{zp}}=\frac{2 F_{\mathrm{p}}}{b \cdot s_{\mathrm{p}}},
\end{aligned}
$$

where $\sigma_{\mathrm{zp}}$ is the vertical compressive stress generated by EVPRs for unit A in the concrete beam.

This study proposes the "vertical compressive stress degree" $\gamma_{\mathrm{p}}$, which is used to characterize the magnitude of the vertical compressive stress generated by EVPRs in the web. The coefficient $\gamma_{\mathrm{p}}$ is calculated as

$$
\gamma_{\mathrm{p}}=\frac{\sigma_{\mathrm{zp}}}{f_{\mathrm{t}}} .
$$

After the EVPRs are configured, the principal tensile stress of unit $\mathrm{A}$ in a critical state of diagonal cracking is reduced from $\sigma_{1}\left(\sigma_{1}=f_{\mathrm{t}}\right)$ to $\sigma_{1 \mathrm{p}}\left(\sigma_{1 \mathrm{p}}<f_{\mathrm{t}}\right)$. In this paper, the "principal tensile stress reduction factor" $\eta_{\mathrm{p}}$ is proposed to characterize the reduction of the principal tensile stress of the EVPR beam relative to the original beam by

$$
\eta_{\mathrm{p}}=\frac{\sigma_{1 \mathrm{p}}}{\sigma_{1}} .
$$

Substituting equations (2), (5), and (6) into equation (7) yields

$$
\eta_{\mathrm{p}}=-\frac{\gamma_{\mathrm{p}}}{2}+\sqrt{\left(\frac{\gamma_{\mathrm{p}}}{2}\right)^{2}+1}
$$

Figure 4 shows the relationship between the principal tensile stress reduction factor $\eta_{\mathrm{p}}$ and the vertical compressive stress degree $\gamma_{\mathrm{p}}$ in the range of $0-2$. The principal tensile stress reduction factor $\eta_{\mathrm{p}}$ decreases with the increase of $\gamma_{\mathrm{p}}$; that is, the principal tensile stress decreases with the increase of the vertical compressive stress, and it is basically close to a linear relationship. Therefore, in practical engineering applications, the vertical compressive stress $\sigma_{\mathrm{zp}}$ can be used to enhance the diagonal crack resistance and shear resistance of the structure. In addition, the vertical compressive stress $\sigma_{\mathrm{zp}}$ provided to the beam by the EVPRs is generally equal to 0.2 to 2 times $f_{\mathrm{t}}\left(f_{\mathrm{t}}\right.$ is the uniaxial tensile strength of concrete). That is, the vertical compressive stress $\sigma_{\mathrm{zp}}$ is generally not

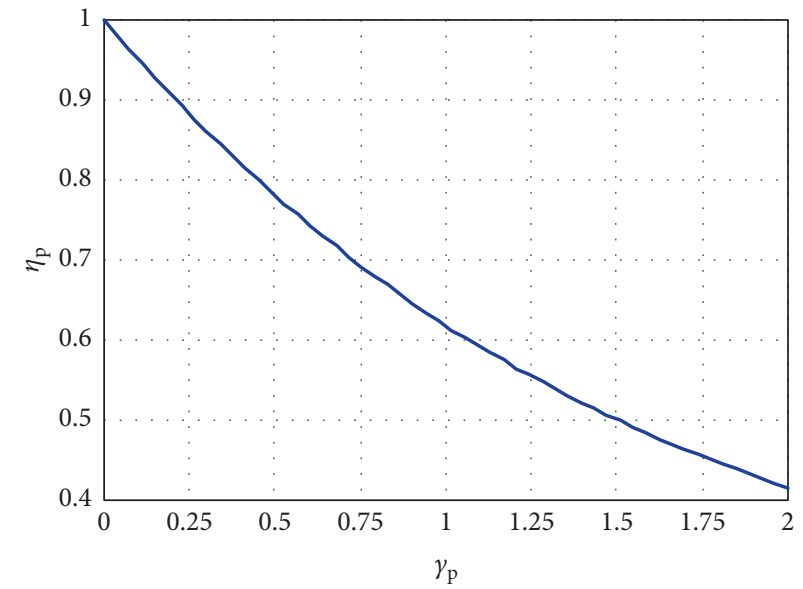

FIGURE 4: Relationship between $\eta_{\mathrm{p}}$ and $\gamma_{\mathrm{p}}$.

greater than 0.2 times $f_{\mathrm{c}}\left(f_{\mathrm{c}}\right.$ is the compressive strength of concrete), and thus, the creep of concrete can be ignored for the negative impact on the benefit from the EVPRs.

2.2. Experimental Specimens and Materials. The magnitude of improvement in load capacity of strengthened beams is a content to be studied in this paper. Because the shear spanto-effective depth ratio affects the stress trajectories, in order to obtain the enhanced effect of EVPRs in shear resisting, the structural types are selected: (1) no web reinforcement and (2) shear span-to-effective depth ratio is greater than 3 to reduce the impact of "concrete arch" on the effect of EVPRs in shear resisting.

A total of seven beams were tested in this study. The geometric properties and reinforcement layout are shown in Figure 1. All the beams with rectangular sectional areas were designed to be reinforced concrete beams. The beam is with a size of $250 \mathrm{~mm}(b) \times 500 \mathrm{~mm}(h) \times 3000 \mathrm{~mm}(l)$ and with a clear span between supports of $2600 \mathrm{~mm}$. All the specimens had five longitudinal tension reinforcements with a diameter of $22 \mathrm{~mm}$ and a reinforcement ratio of $1.81 \%$ recorded as $\Phi 22$ and had two longitudinal compression reinforcements with a diameter of $22 \mathrm{~mm}$ recorded as $\Phi 22$.

In the longitudinal direction of the beam, the specimens were divided into two segments: the left segment without stirrups and the right segment with embedded stirrups, as shown in Figure 1. Stirrups with a spacing of $100 \mathrm{~mm}$, a diameter of $12 \mathrm{~mm}$, and a stirrup ratio of $0.905 \%$ were 
embedded in the right segment to avoid shear failure. The segment without stirrups is the expected zone to encounter shear failure in the RC members and EVPR members.

The properties of the specimens are summarized in Table 1. In Table 1, in addition to the above mentioned principal parameters, such as the principal tensile stress reduction factor $\eta_{\mathrm{p}}$ and vertical compressive stress degree $\gamma_{\mathrm{p}}$, there is an important parameter $\rho_{\mathrm{sEP}}$, the stirrup ratio of EVPRs, which is calculated as

$$
\rho_{\mathrm{sEP}}=\frac{A_{\mathrm{sEP}}}{b \cdot s_{\mathrm{p}}},
$$

where $A_{\mathrm{sEP}}$ is the total area of the EVPRs in one section, $b$ is the width of the beam, and $s_{\mathrm{p}}$ is the spacing of the EVPRs.

In this study, specimens are designated by four characters. The first character "RC" and the second one "EP" are the abbreviation of reinforced concrete beams and EVPR beams, respectively. The third character "F" shows the pulling force value added to every EVPR, and its unit is $\mathrm{kN}$. The last character " $\mathrm{S}$ " shows the spacing of the EVPRs. S1, S2, and S3 represent $340 \mathrm{~mm}, 240 \mathrm{~mm}$, and $280 \mathrm{~mm}$, respectively. According to the above definitions, EP_P22_S2 means that the specimen is strengthened by EVPRs, the pulling force value added to every EVPR is $22 \mathrm{kN}$, and the spacing of the EVPRs is $240 \mathrm{~mm}$; RC_1 means that the beam is the first one of the reinforced concrete beams.

The specimens consist of seven beams, which were divided into two experimental groups. One group is enhanced by EVPRs, called EVPR members, and another group is not enhanced by EVPRs, called RC members. The RC members are the control beams, including RC_1 and RC_2, which are designed to have weaker shear strength than flexural strength to a large extent. The EVPR members, consisting of EP_P22_S1, EP_P18_S3, EP_P22_S2, and EP_P26_S3, are designed to examine the effects of different stirrup ratios of EVPRs on the shear behavior under the same vertical compressive stress degree. In addition, EVPR members EP_P22_S3, EP_P26_S3, and EP_P18_S3 are designed to examine the effects of different vertical compressive stress degrees on the shear behavior under the same stirrup ratio of EVPRs.

The concrete used consists of water, PO 32.5 cement, fine sand, and coarse aggregates with a maximum diameter of $16 \mathrm{~mm}$. The mixing ratio is shown in Table 2.

The cubic compressive strength and cubic splitting strength of concrete were obtained from the standard cube tests of the 15 samples with dimensions of $150 \mathrm{~mm} \times$ $150 \mathrm{~mm} \times 150 \mathrm{~mm}$. The mean values of the cubic compressive strength $f_{\mathrm{c}}$ and cubic splitting strength $f_{\mathrm{ts}}$ are $30.2 \mathrm{MPa}$ and $2.88 \mathrm{MPa}$, respectively.

Two types of steel bars for the longitudinal reinforcement recorded as $\Phi 22$ and the stirrups recorded as $\Phi 12$ were used in the cast-in-place beam. The EVPRs used to enhance the segment without the stirrups of the beams are ribbed steel with a diameter of $14 \mathrm{~mm}$. The characteristics of these three types of steel bars were evaluated by the elastic modulus $E_{\mathrm{s}}$, the yield strength $f_{\mathrm{y}}$, and the ultimate strength $f_{\mathrm{u}}$, as shown in Table 3.
2.3. Strengthening Technique. An EVPR anchoring unit used in strengthening the beam is shown in detail in Figure 5. The structure system of an EVPR anchoring unit consists of the following elements: (1) double steel bars, with $14 \mathrm{~mm}$ diameter and $800 \mathrm{~mm}$ length, prestressed before the beam is loaded; (2) a double anchoring beam for transferring the prestressed force: the anchoring beam consists of two 10\# channels steel welded with three $10 \mathrm{~mm}$ thick reinforcing plates to ensure sufficient stiffness; (3) M14 nuts to connect the prestressing steel bars and anchoring beam; and (4) four $10 \mathrm{~mm}$ thick backing plates with a $20 \mathrm{~mm}$ diameter hole to avoid stress concentration.

The process of applying the EVPR system to a concrete beam is as follows: First, various components of the EVPR anchoring unit are initially installed. Then, the strain gauge is placed on each of the prestressing steel bars. Next, the nuts are slowly and manually screwed to apply the prestress, and the strain is read in real time through the strain gauge. Finally, the tensile force is obtained until the tensile force reaches the design value.

\subsection{Experimental Setup and Instrumentation. Specimens} were tested under concentrated stationary loads by using a hydraulic jack, which is $1400 \mathrm{~mm}$ and $1200 \mathrm{~mm}$ from the left and right supports, respectively. A rubber plate unit was used under the load cell to ensure the transfer of uniform pressure to the specimens. The load was applied against a structural steel frame connected to the floor.

To effectively control the tensioning process and obtain the tensile force value of the EVPR during the test, strain gauges were placed on every EVPR, numbered PS1, PS2, PS3, and PS4 from left to right. In addition, " $R$ " and " $L$ " were used to indicate that the strain gauge is on the right or left of the beam. Three strain gauges, namely, TS1, TS2, and TS3, were placed on each tensile reinforcement to obtain strain during loading. In the right segment with stirrups, a strain gauge was placed on one of the stirrups to measure its strain, as shown in Figure 6.

Tension was applied to EVPRs by manually tightening the nuts until the tensile force reached the design value. By pushing the hydraulic jack for loading, the loading rate was approximately $20 \mathrm{kN} / 5$ minutes and was maintained for 15 minutes. The actual loading force was obtained by the load cell (capacity: $1000 \mathrm{kN}$, model: YLR-3F) under the hydraulic jack. Deflections at the midspan were measured using a potentiometer of $50 \mathrm{~mm}$ stroke with an accuracy of $0.01 \mathrm{~mm}$. The data of the strain gauge and load cell were obtained by a static resistance strain gauge (model: TYPEB2930).

\section{Test Results and Discussion}

Seven beams without web reinforcements, including 5 beams enhanced by EVPRs and 2 beams not enhanced, were tested to analyze the effect of EVPRs on the shear resistance, in cases where the shear span-to-effective depth ratio is greater than 3 . The test variables are the stirrup ratio, arrangement spacing, prestressing force, and vertical 
TABLE 1: Main parameters of the specimens.

\begin{tabular}{|c|c|c|c|c|c|c|c|c|c|c|}
\hline \multirow[b]{2}{*}{ Specimen } & \multirow{2}{*}{$\begin{array}{c}\text { Dimension } \\
b \times h \times l\left(\mathrm{~mm}^{3}\right)\end{array}$} & \multirow[b]{2}{*}{ Stirrups } & \multirow{2}{*}{$\begin{array}{l}\text { Longitudinal } \\
\text { tension rebars }\end{array}$} & \multirow{2}{*}{$\begin{array}{c}\text { Longitudinal } \\
\text { compression rebars }\end{array}$} & \multicolumn{4}{|c|}{ EVPR } & \multirow[b]{2}{*}{$\gamma_{\mathrm{p}}$} & \multirow[b]{2}{*}{$\eta_{\mathrm{p}}$} \\
\hline & & & & & $\begin{array}{l}\text { Diameter } \\
(\mathrm{mm})\end{array}$ & $\begin{array}{l}\text { Spacing } \\
(\mathrm{mm})\end{array}$ & $\begin{array}{c}\text { Pulling } \\
\text { force }(\mathrm{kN})\end{array}$ & $\begin{array}{l}\rho_{\text {sEP }} \\
(\%)\end{array}$ & & \\
\hline RC_1 & $250 \times 500 \times 3000$ & $\begin{array}{c}\Phi 12 @ \\
100\end{array}$ & $5 \Phi 22$ & $2 \Phi 22$ & - & - & - & - & - & - \\
\hline $\mathrm{RC} \_2$ & $250 \times 500 \times 3000$ & $\begin{array}{c}\Phi 12 @ \\
100\end{array}$ & $5 \Phi 22$ & $2 \Phi 22$ & - & - & - & - & - & - \\
\hline EP_P22_S1 & $250 \times 500 \times 3000$ & $\begin{array}{c}\Phi 12 @ \\
100\end{array}$ & $5 \Phi 22$ & $2 \Phi 22$ & 14 & 340 & 22 & 0.36 & 0.20 & 0.91 \\
\hline EP_P22_S2 & $250 \times 500 \times 3000$ & $\begin{array}{c}\Phi 12 @ \\
100\end{array}$ & $5 \Phi 22$ & $2 \Phi 22$ & 14 & 240 & 22 & 0.51 & 0.28 & 0.87 \\
\hline EP_P22_S3 & $250 \times 500 \times 3000$ & $\begin{array}{c}\Phi 12 @ \\
100\end{array}$ & $5 \Phi 22$ & $2 \Phi 22$ & 14 & 280 & 22 & 0.44 & 0.24 & 0.89 \\
\hline EP_P26_S3 & $250 \times 500 \times 3000$ & $\begin{array}{c}\Phi 12 @ \\
100\end{array}$ & $5 \Phi 22$ & $2 \Phi 22$ & 14 & 280 & 26 & 0.44 & 0.28 & 0.87 \\
\hline EP_P18_S3 & $250 \times 500 \times 3000$ & $\begin{array}{c}\Phi 12 @ \\
100\end{array}$ & $5 \Phi 22$ & $2 \Phi 22$ & 14 & 280 & 18 & 0.44 & 0.20 & 0.91 \\
\hline
\end{tabular}

TABle 2: Concrete mix ratio.

\begin{tabular}{|c|c|c|c|c|c|}
\hline Water $\left(\mathrm{kg} / \mathrm{m}^{3}\right)$ & Cement $\left(\mathrm{kg} / \mathrm{m}^{3}\right)$ & Fine sand $\left(\mathrm{kg} / \mathrm{m}^{3}\right)$ & Coarse aggregate $\left(\mathrm{kg} / \mathrm{m}^{3}\right)$ & Water-cement ratio $\left(\mathrm{kg} / \mathrm{m}^{3}\right)$ & Sand content $(\%)$ \\
\hline 175 & 461 & 512 & 1252 & 0.38 & 29 \\
\hline
\end{tabular}

Table 3: Properties of steel bars.

\begin{tabular}{|c|c|c|c|c|}
\hline Type & Diameter $(\mathrm{mm})$ & $f_{\mathrm{y}}(\mathrm{MPa})$ & $f_{\mathrm{u}}(\mathrm{MPa})$ & $E_{\mathrm{s}}(\mathrm{MPa})$ \\
\hline EVPR & 14 & 300 & 515 & $2.1 \times 10^{5}$ \\
\hline Stirrup & 12 & 445 & 630 & $2.0 \times 10^{5}$ \\
\hline Longitudinal reinforcement & 22 & 455 & 670 & $2.0 \times 10^{5}$ \\
\hline
\end{tabular}

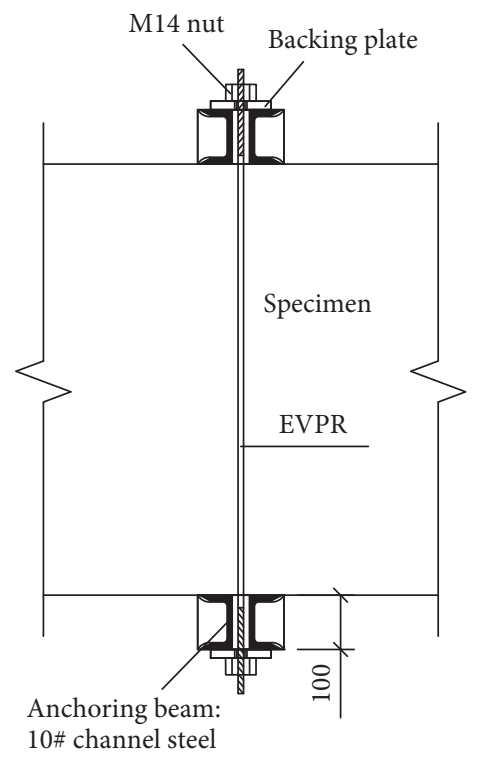

(a)

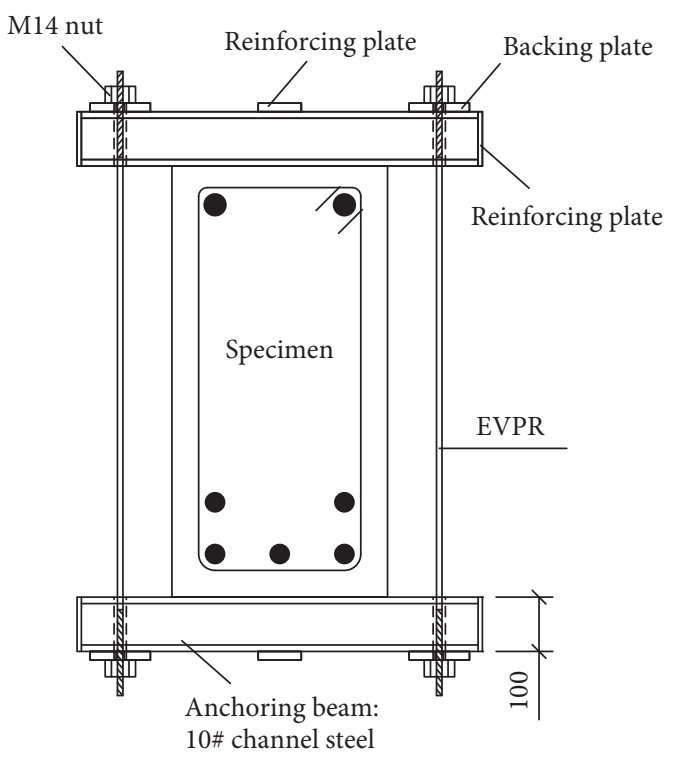

(b)

FIGURE 5: Structure form of the beam strengthened by the EVPRs (unit: mm). 


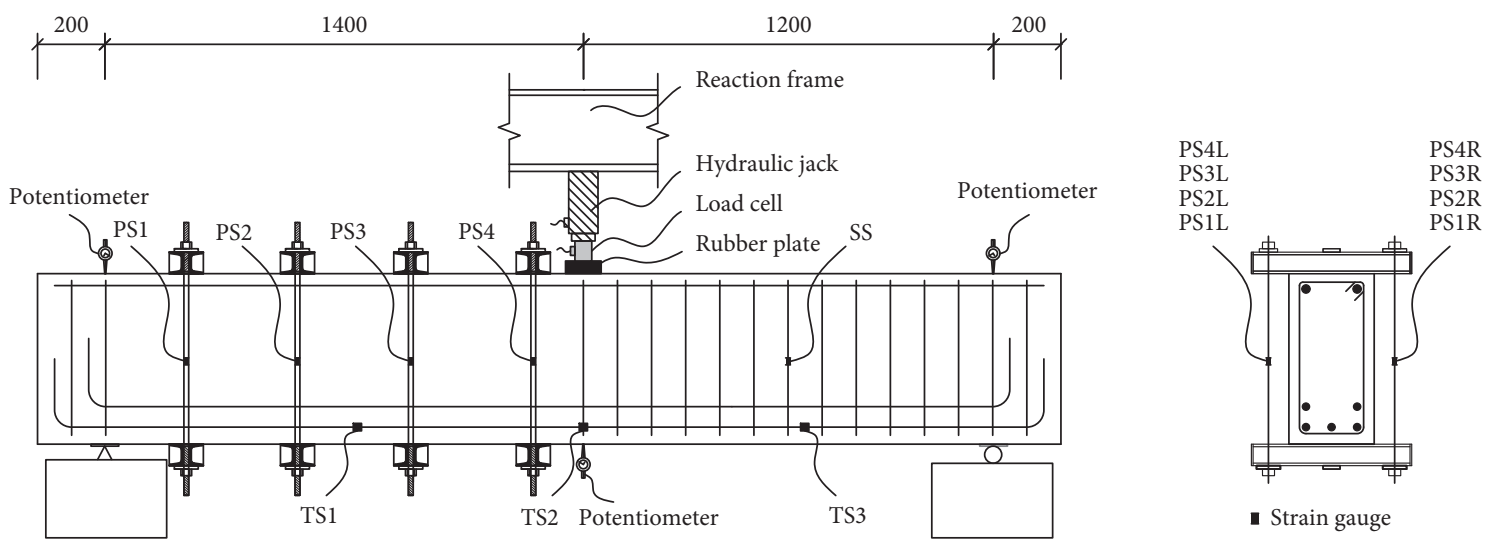

FIGURE 6: Loading device and measuring point arrangement (unit: $\mathrm{mm}$ ).

compressive stress degree of the EVPRs. The test results mainly introduce crack development, failure mode, steel stress, and shear capacity.

3.1. Shear Capacity and Failure Mode. As a theoretical system, critical shear crack theory (CSCT) has been applied to the analysis of shear behavior of concrete structures in recent years. An important feature of this theory is the critical shear crack (CSC), [30] which is suitably defined as follows: after the shear cracking, further loading causes the number of shear cracks to increase or to widen, eventually forming a major shear crack. Normally, the failure of the concrete specimen is mainly caused by the opening of the CSC, but the final failure surface does not always coincide with the CSC. When the failure surface of the specimen occurs at the CSC, it is called the A-F type. When the failure surface is partly coincident with the CSC, it is called the A-E type. Based on a large amount of experimental data, Muttoni $[31,32]$ simplified the CSC into a double-fold model (A-B$\mathrm{F}$ ), as shown in Figure 7. In general, the process of forming and widening CSC can be used as a feature in shear crack development of the concrete specimen. This article refers to the load $P_{\text {CSC }}$ applied to form CSC in later chapters, which mainly considers the moment when the A-B segment has formed and the B-F segment is about to form.

Table 4 shows a summary of the crack development, displacement, bearing capacity, and failure mode of the test beam with load development.

Since the RC_1 and RC_2 beams are not configured with stirrups in the left segment and the shear span-to-effective depth ratio is relatively large $(a / d=3.33)$, typically, shear diagonal tension failure occurs at loads of $255 \mathrm{kN}$ and 290 kN, which are brittle shear failures. For RC_1 and RC_2, once the diagonal tension failure is formed, the brittle shear failure occurs immediately (Figure 8).

After the EVPR is configured, all EVPR specimens, namely, EP_P22_S1, EP_P22_S2, EP_P22_S3, EP_P26_S3, and EP_P18_S3, have been transformed from diagonal tension failure to shear compression failure due to the action of vertical compressive stress, and the shear capacity is increased to $505 \mathrm{kN}-535.2 \mathrm{kN}$. The shear capacity is increased by $85.3 \%-96.4 \%$ relative to the mean of RC_1 and
RC_2. At the same time, there is an ability to exhibit good ductility, as shown in Figure 8.

Figure 8 shows the following: (1) overall, when the compressive stress degree $\gamma_{\mathrm{p}}$ is constant, the shear capacity of the beam increases with the increase in the EVPR stirrup ratio obtained from specimens EP_P22_S1, EP_P18_S3, EP_P22_S2, and EP_P26_S3 and (2) since the stirrup ratio of the EVPRs $\rho_{\mathrm{sEP}}$ is constant, the shear capacity increases with the increase in the compressive stress degree $\gamma_{\mathrm{p}}$ according to specimens EP_P22_S3, EP_P26_S3, and EP_P18_S3; this means that when the tensile force of the EVPRs is constant, the shear capacity increases as the spacing of the EVPRs decreases, and when the spacing of the EVPRs is constant, the shear capacity increases as the tensile force of the EVPRs increases.

3.2. Crack Pattern. The failure modes of the seven specimens are shear failure, and all of the shear failures occur in the left segments, which embedded no stirrups. The right segment of all specimens does not fail since there are enough stirrups, but many cracks exist in the specimens in the test. The following information only describes the test results of the left segments. Figure 9 shows the crack pattern of the test beam at shear failure, as mainly represented by specimens RC_1, RC_2, EP_P22_S2, and EP_P26_S3. At the same time, in order to show the crack pattern more clearly, Figure 10 depicts the crack distribution of all the specimens. The specific analysis is as follows.

3.2.1. RC Members. When the load is $70 \mathrm{kN}-80 \mathrm{kN}$, the flexural cracks started to be generated at the bottom position of the midspan of the specimens. As the load increased further, several new flexural cracks appeared in the direction of the loading point toward the support. When loaded to $255 \mathrm{kN}$ and $290 \mathrm{kN}$, the critical shear crack (CSC) suddenly formed and immediately widened. With a crisp sound, diagonal tension failure was ultimately caused, and only one diagonal crack formed.

Since the RC_1 and RC_2 beams are not configured with stirrups in the left segment and the shear span-to-effective depth ratio is relatively large $(a / d=3.33)$, typical shear 


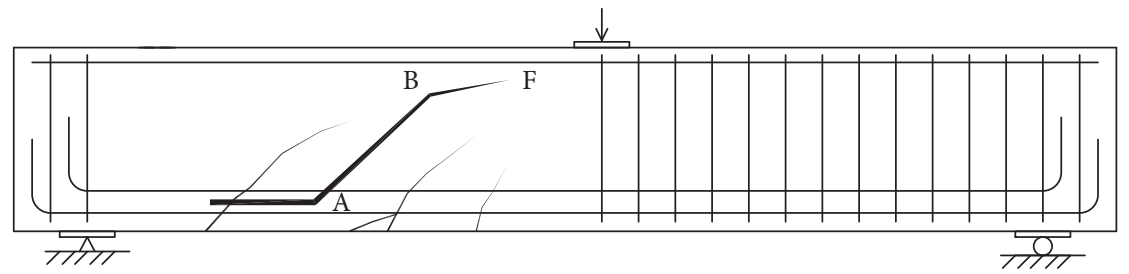

Figure 7: Simplified model of the CSC (A-B-F) [32].

TABle 4: Main experimental results.

\begin{tabular}{lcccccccc}
\hline Specimen & $\gamma_{\mathrm{p}}$ & $\eta_{\mathrm{p}}$ & $P_{\mathrm{MC}}(\mathrm{kN})$ & $P_{\mathrm{SC}}(\mathrm{kN})$ & $P_{\mathrm{CSC}}(\mathrm{kN})$ & $P_{\mathrm{U}}(\mathrm{kN})$ & $\delta_{\mathrm{U}}(\mathrm{mm})$ & Failure mode \\
\hline RC_1 & 0 & 1 & 70 & - & - & 255 & 3.04 & DT \\
RC_2 & 0 & 1 & 80 & - & - & 290 & 3.76 & DT \\
EP_P22_S1 & 0.20 & 0.91 & 69.10 & 159.40 & 314.5 & 505.0 & 16.54 & SC \\
EP_P22_S2 & 0.28 & 0.87 & 75.60 & 199.30 & 318.5 & 519.5 & 9.85 & SC \\
EP_P22_S3 & 0.24 & 0.89 & 89.80 & 183.20 & 307.2 & 527.6 & 12.20 & SC \\
EP_P26_S3 & 0.28 & 0.87 & 75.90 & 144.50 & 328.4 & 535.2 & 21.06 & SC \\
EP_P18_S3 & 0.20 & 0.91 & 96.90 & 159.40 & 308.6 & 517.6 & 9.88 & SC \\
\hline
\end{tabular}

$P_{\mathrm{MC}}$ is the load corresponding to the first flexural crack; $P_{\mathrm{SC}}$ is the load corresponding to the first shear crack; $P_{\mathrm{CSC}}$ is the load applied to form CSC; $P_{\mathrm{U}}$ is the load at shear capacity; $\delta_{\mathrm{U}}$ is the midspan displacement at shear failure; DT represents diagonal tension failure; SC represents shear compression failure.

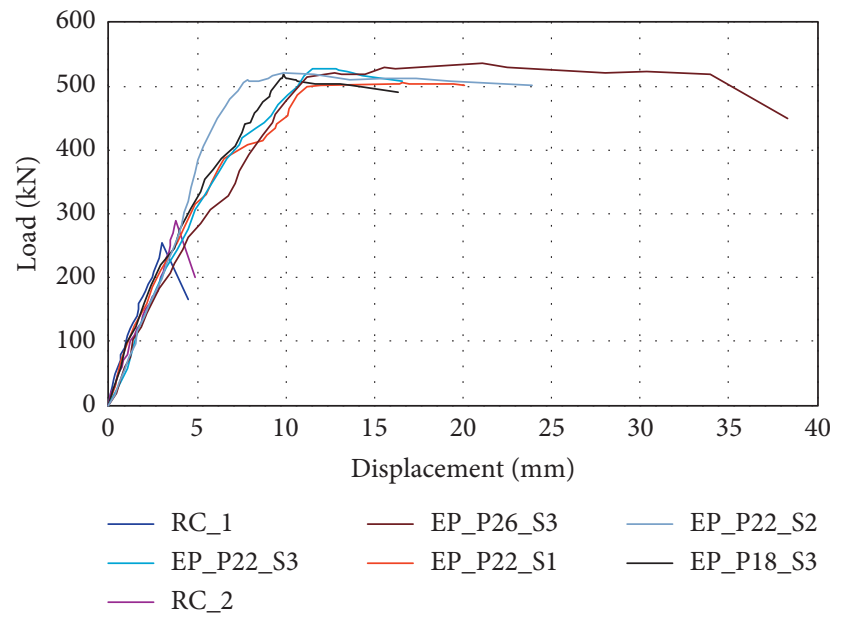

FIGURE 8: Load-displacement responses.

diagonal tension failure occurs at loads of $255 \mathrm{kN}$ and $290 \mathrm{kN}$, which is brittle failure. The crack development was less, except for a few flexural cracks. There was only a diagonal crack causing one specimen failure, as shown in Figures 9(a), 9(b), 10(a), and 10(b).

3.2.2. EVPR Members. It can be seen from Figure 8 that the shear capacity and ductility of all EVPR specimens are greatly improved after the EVPRs are arranged.

In all EVPR members, including EP_P22_S1, EP_P22_S2, EP_P22_S3, EP_P26_S3, and EP_P18_S3, shear compression failure occurred and a number of diagonal cracks and flexural cracks were formed. Although shear compression failure is also brittle failure, it can continue to bear the load after reaching the ultimate shear capacity. Compared with the RC_1 and RC_2 beams, the ductility was greatly improved. The ability to exhibit good ductility at the same time is mainly due to the shear contribution of EVPRs since the stirrup and vertical compressive stress originated from the EVPRs.

When the loads were $69.1 \mathrm{kN}, 75.6 \mathrm{kN}, 89.8 \mathrm{kN}$, $75.9 \mathrm{kN}$, and $96.9 \mathrm{kN}$, respectively, specimens EP_P22_S1, EP_P22_S2, EP_P22_S3, EP_P26_S3, and EP_P18_S3 produced their first flexural crack. As the load increased further, a number of flexural cracks near the support gradually emerged. When the loads were $159.4 \mathrm{kN}$, $199.3 \mathrm{kN}, 183.2 \mathrm{kN}, 144.5 \mathrm{kN}$, and $159.4 \mathrm{kN}$, respectively, the flexural cracks developed into diagonal cracks. When further loaded to $314.5 \mathrm{kN}, 318.5 \mathrm{kN}, 307.2 \mathrm{kN}, 328.4 \mathrm{kN}$, and $308.6 \mathrm{kN}$, the shapes of the critical shear crack (CSC) were formed, but due to the enhancement of EVPRs, the specimens worked well still. As the load increased, the critical diagonal crack gradually widened until the specimens' shear failure. The load forces at shear failure were $505.03 \mathrm{kN}, 519.11 \mathrm{kN}, 527.62 \mathrm{kN}, 535.21 \mathrm{kN}$, and $517.6 \mathrm{kN}$, respectively. It can be seen that the EVPRs have little effect on the initial flexural crack load of the specimens, but the diagonal crack load increases with the increase in the vertical compressive stress degree. Due to the action of EVPRs, both flexural cracks and diagonal cracks are fully developed.

Meanwhile, when the shear failure occurred, the results of the strain reading of the TS1-TS3 gauges showed that the tension stresses of the longitudinal tension rebars are all less than $2.275 \times 10^{-3}$; this means that the longitudinal tension rebars are not yielded, indicating that the beams only suffered shear failure without flexural failure. Due to the effect of compressive stress and without the constraints of the stirrups, the longitudinal compression rebars at the top of the specimen exhibit lateral buckling under compression, causing a large amount of concrete on the side to peel off. During the loading process, the anchoring beam, consisting of two steel-welded 10\# channels, gradually shows local 


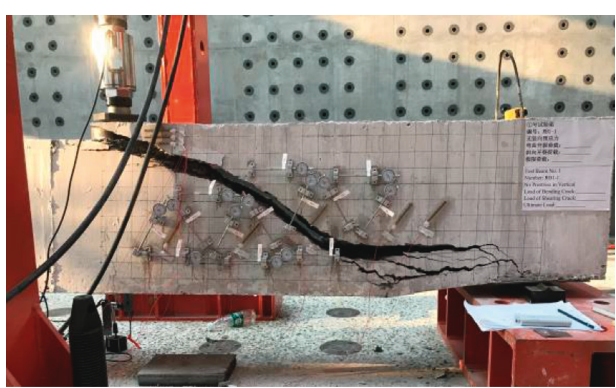

(a)

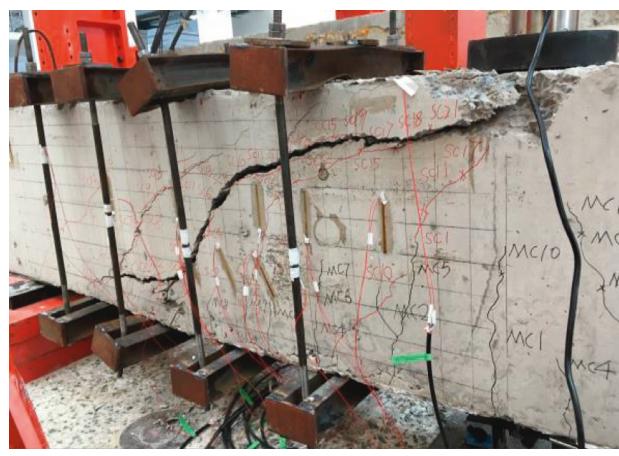

(c)

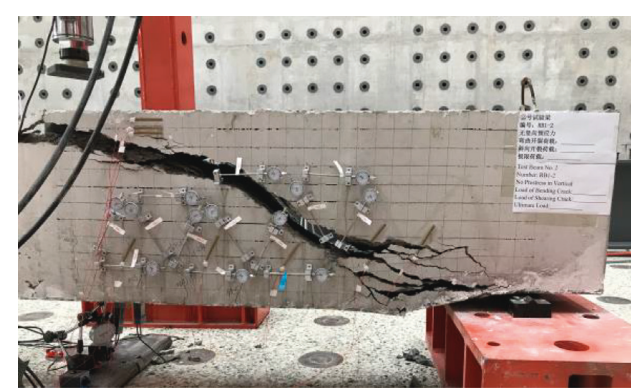

(b)

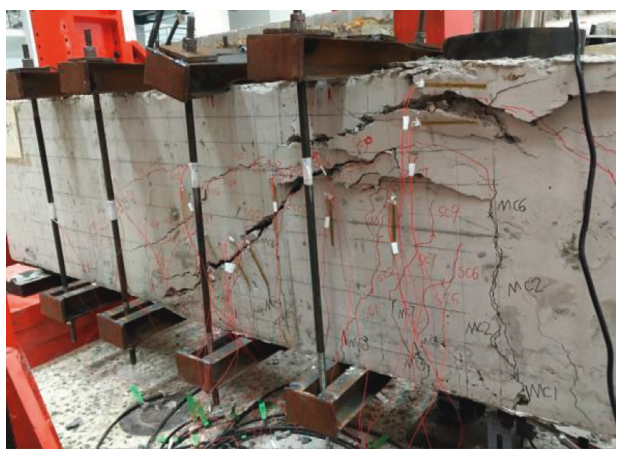

(d)

FIGURE 9: Pictures of cracking patterns at shear failure for partial specimens. (a) RC_1. (b) RC_2. (c) EP_P22_S2. (d) EP_P26_S3.

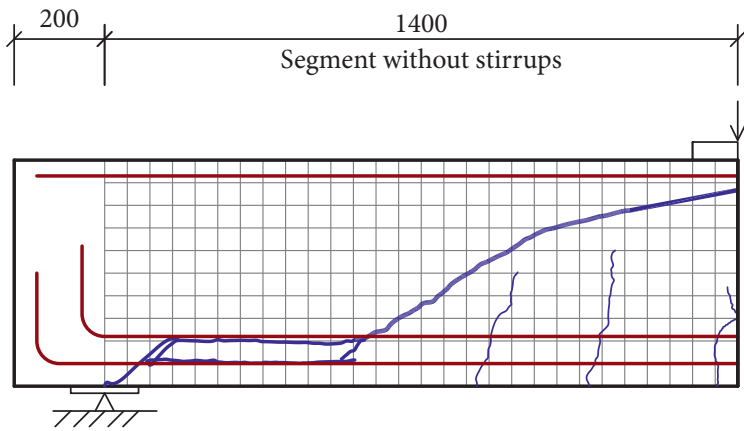

(a)

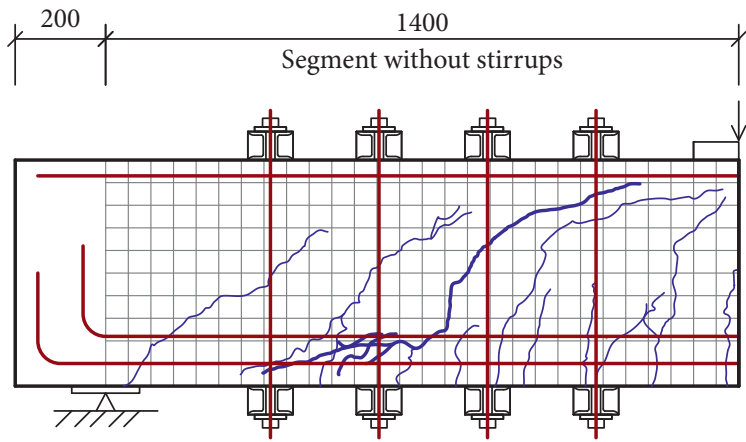

(c)

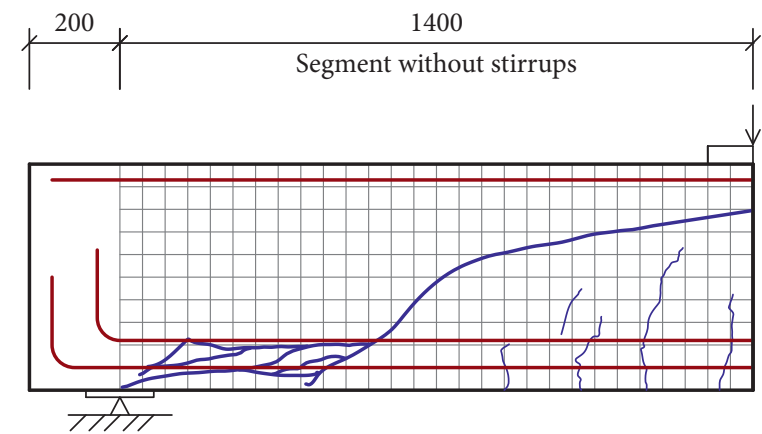

(b)

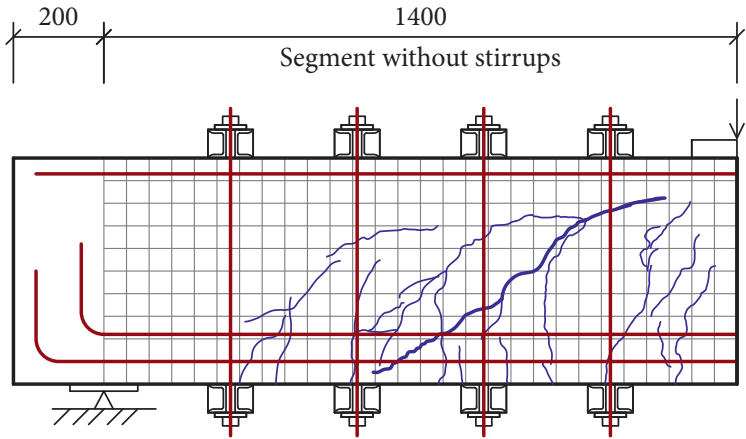

(d)

Figure 10: Continued. 


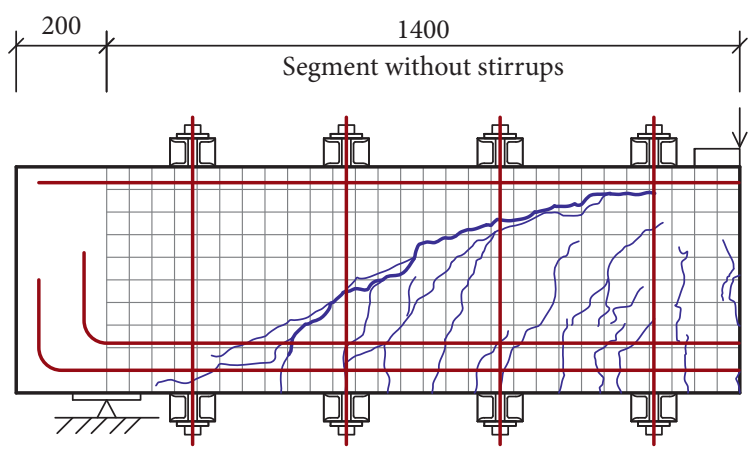

(e)

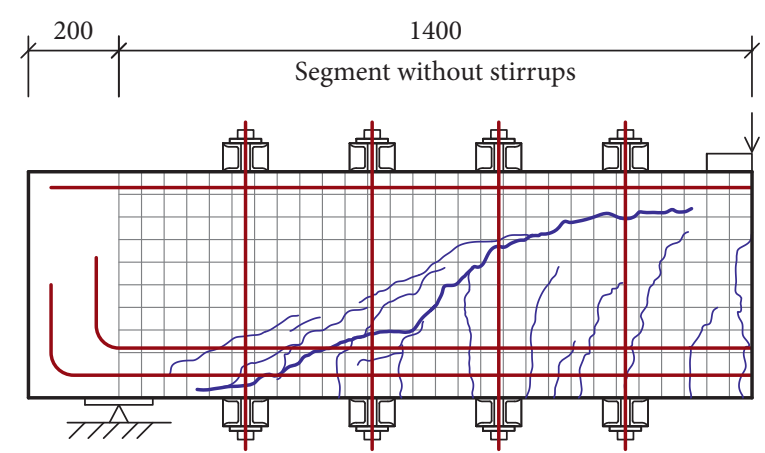

(f)

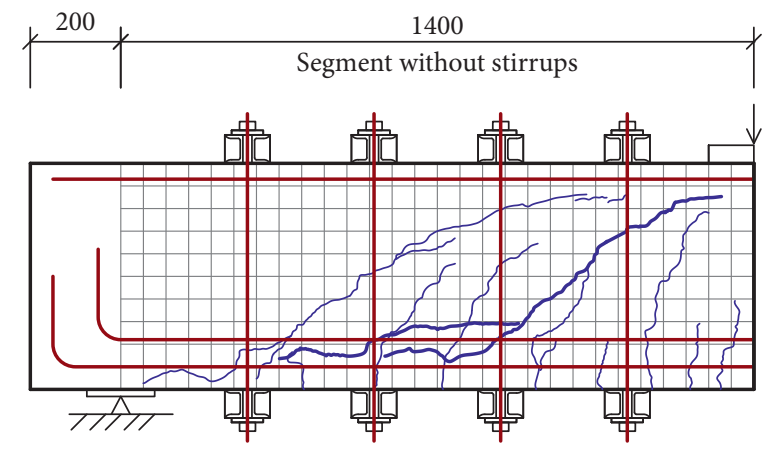

(g)

FIGURE 10: Depiction of the cracking pattern at shear failure for all the specimens. (a) RC_1. (b) RC_2. (c) EP_P22_S2. (d) EP_P26_S3. (e) EP_P22_S1. (f) EP_P18_S3. (g) EP_P22_S3.

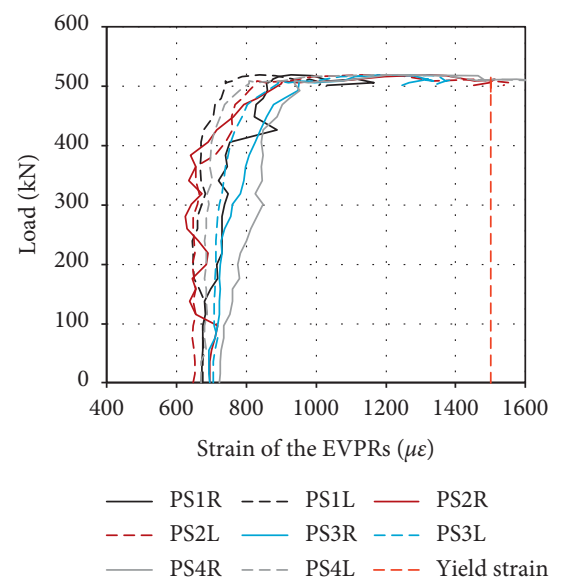

(a)

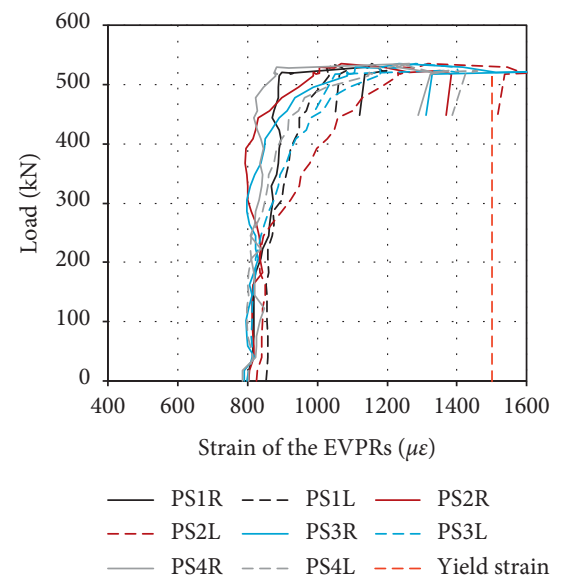

(b)

Figure 11: Continued. 


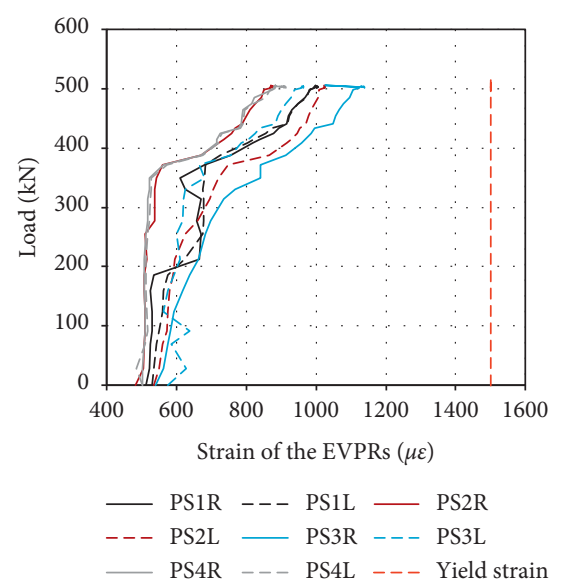

(c)

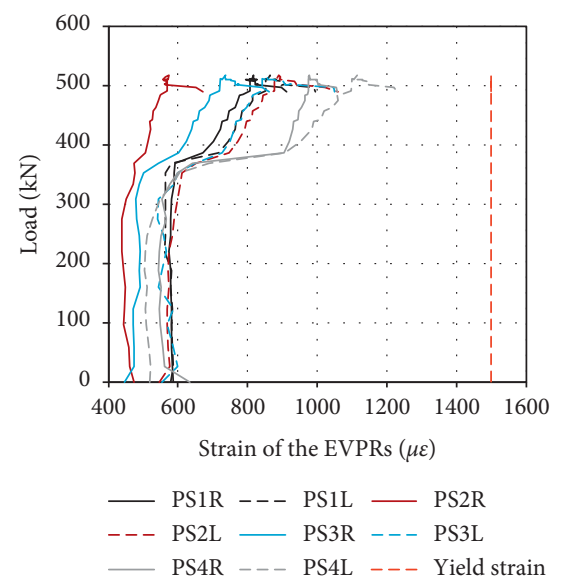

(d)

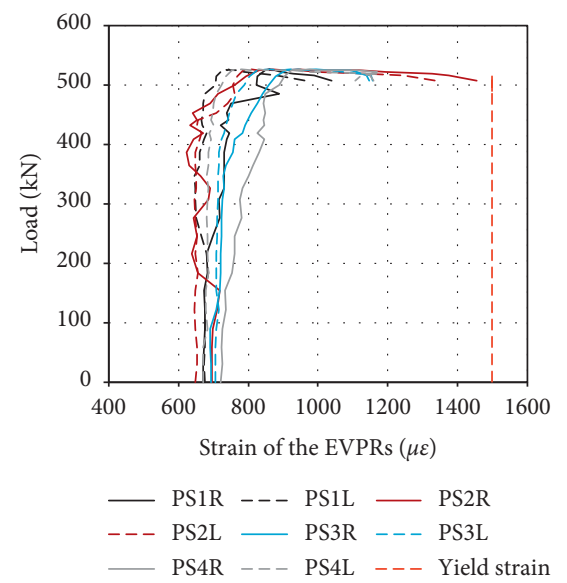

(e)

Figure 11: Strain of the EVPRs. (a) RB2-P22-S2. (b) RB2-P26-S3. (c) RB2-P22-S1. (d) RB2-P18-S3. (e) RB2-P22-S3.

flange buckling, especially at the upper area near the loading point, as shown in Figures 9(c) and 9(d).

3.3. Strain of the Prestressing Rebars. Figure 11 shows the strain variation of the EVPR with the loading force. It can be seen that the strain of the EVPR changes little before formation of the CSC, but the change increases sharply after formation of the CSC until the EVPR reaches yield.

The reason is that, according to the classical assumption of elastic mechanics, in the vertical direction, the concrete structure satisfies the small deformation assumption before the shear cracking, so the strain change in the EVPR is small; at this stage, due to the vertical compressive stress, the principal tensile stress of the concrete at the segment without stirrups is less than its tensile strength.

After the CSC is formed, due to the shear force, the specimen body begins to produce large deformation in the vertical direction, and the strain of the EVPR increases sharply. At this stage, the EVPR acts as a stirrup until the structure exhibits shear failure. Therefore, the antishear contribution of the EVPR mainly includes (1) the shear resistance of concrete enhanced by the vertical compressive stress and (2) that it bears the shear force as a stirrup in the stage from the formation of the CSC to the shear failure.

\section{Conclusions}

In this study, the test results of seven beams with shear spanto-effective depth ratio $a / d=3.33$ are given, including two concrete specimens without stirrups and five concrete ones enhanced by EVPRs. The test parameters include the stirrup ratio, arrangement spacing, prestressing force, and vertical compressive stress degree of the EVPRs, and the concept of vertical compressive stress degree $\gamma_{\mathrm{p}}$ and principal tensile stress reduction factor $\eta_{p}$ is proposed. Based on analysis of the test results, the following conclusions can be drawn:

(1) Due to the shear contribution of the EVPRs as a stirrup and the vertical compressive stress originated from the EVPRs, the shear compression failure occurs in the EVPR specimens, instead of the diagonal tension failure of the control group. Not only can the shear capacity of concrete beams without web reinforcement be improved significantly by the EVPRs, but also EVPR members exhibit better ductility and 
their flexural cracks and shear cracks develop more fully.

(2) The shear capacity of the beam increases with the increase in the stirrup ratios of the EVPRs and the compressive stress degree. When the tensile force of the EVPR is constant, the shear capacity increases when the spacing of the EVPRs decreases.

(3) The vertical compressive stress can reduce the principal tensile stress of the concrete structure to prevent shear cracking and enhance the shear performance of the concrete, and the EVPR shares shear load as a stirrup in the stage from the formation of the CSC to the shear failure.

In general, EVPRs are an active and effective method to enhance shear resistance of concrete structures. However, there are some limitations in applying the EVPRs to damaged concrete beams: EVPRs have an impact on the aesthetics of the original structure, and sometimes, their anchoring measures are not convenient even disable to be installed.

\section{Data Availability}

The data used to support the findings of this study are available from the corresponding author upon request.

\section{Conflicts of Interest}

The authors declare that they have no conflicts of interest regarding the publication of this article.

\section{Authors' Contributions}

Xue X. W. and Zhou J. L. performed the methodologies, supervised the study, wrote the original draft, and reviewed and edited the article. Xuan W. and Hua X. D. performed the methodologies and investigation. Data curation was performed by Wu M. Z., Wu L. Q., and Ma Z.

\section{Acknowledgments}

The authors wish to acknowledge the financial support of the Basic Research Project for Universities of Liaoning Province (Grant no. LJZ2017043) and the Postdoctoral Innovation Fund Project of Shenyang Jianzhu University (Grant no. SJZUBSH201712).

\section{References}

[1] H.-S. Lee, H.-O. Jang, and K.-H. Cho, "Evaluation of bonding shear performance of ultra-high-performance concrete with increase in delay in formation of cold joints," Materials, vol. 9, no. 5 , p. $362,2016$.

[2] A. P. Lampropoulos, S. A. Paschalis, O. T. Tsioulou, and S. E. Dritsos, "Strengthening of reinforced concrete beams using ultra high performance fibre reinforced concrete (UHPFRC)," Engineering Structures, vol. 106, pp. 370-384, 2016.

[3] Z. M. Yaseen, M. T. Tran, S. Kim, T. Bakhshpoori, and R. C. Deo, "Shear strength prediction of steel fiber reinforced concrete beam using hybrid intelligence models: a new approach," Engineering Structures, vol. 177, pp. 244-255, 2018.

[4] K. Ma, T. Qi, H. Liu, and H. Wang, "Shear behavior of hybrid fiber reinforced concrete deep beams," Materials, vol. 11, no. 10, p. 2023, 2018.

[5] H. J. Qureshi and M. U. Saleem, "Flexural and shear strain characteristics of carbon fiber reinforced polymer composite adhered to a concrete surface," Materials, vol. 11, no. 12, p. 2596, 2018.

[6] S. A. Ashour, G. S. Hasanain, and F. F. Wafa, "Shear behavior of high-strength fiber reinforced concrete beams," $A C I$ Structural Journal, vol. 89, no. 2, pp. 176-184, 1992.

[7] S. Altin, Ö. Anil, and M. E. Kara, "Improving shear capacity of existing RC beams using external bonding of steel plates," Engineering Structures, vol. 27, no. 5, pp. 781-791, 2005.

[8] S. Pour, M. Alam, and A. Milani, "Improved bond equations for fiber-reinforced polymer bars in concrete," Materials, vol. 9, no. 9, p. 737, 2016.

[9] M. Guadagnini, K. Pilakoutas, and P. Waldron, "Shear resistance of FRP RC beams: experimental study," Journal of Composites for Construction, vol. 10, no. 6, pp. 464-473, 2006.

[10] R. H. Haddad, R. Z. Al-Rousan, and B. K. Al-Sedyiri, "Repair of shear-deficient and sulfate-damaged reinforced concrete beams using FRP composites," Engineering Structures, vol. 56, pp. 228-238, 2013.

[11] R. Al-Rousan and R. Haddad, "NLFEA sulfate-damage reinforced concrete beams strengthened with FRP composites," Composite Structures, vol. 96, pp. 433-445, 2013.

[12] R. Z. Al-Rousan, R. H. Haddad, and A. O. Swesi, "Repair of shear-deficient normal weight concrete beams damaged by thermal shock using advanced composite materials," Composites Part B: Engineering, vol. 70, pp. 20-34, 2015.

[13] S. J. Seguirant, R. Brice, and B. Khaleghi, "Time-dependent prestress losses in post-tensioned spliced girders made of high performance concrete," in Proceedings of the Concrete Bridge Conference, Charlotte, NC, USA, October 2004.

[14] Z. Fang and J. Wang, "Vertical prestressing loss in the box girder of long-span PC continuous bridges," China Civil Engineering Journal, vol. 5, no. 39, pp. 78-84, 2006.

[15] M. Y. Shen, X. G. Zhong, and X. W. Liu, "Experimental study on the loss of vertical prestress in the webs of concrete box girders," Engineering Mechanics, vol. 27, no. 9, 2010.

[16] M. Fiset, J. Bastien, and D. Mitchell, "Shear strengthening of concrete members with unbonded transverse reinforcement," Engineering Structures, vol. 180, pp. 40-49, 2019.

[17] R. S. Aboutaha and N. Burns, "Shear strengthening of pretensioned prestressed concrete composite flexural members," Posttensioning, 1991.

[18] S. Altin, T. Tankut, Ö. Anil, and Y. Demirel, "Response of reinforced concrete beams with clamps applied externally: an experimental study," Engineering Structures, vol. 25, no. 9, pp. 1217-1229, 2003.

[19] B. B. Adhikary and H. Mutsuyoshi, "Shear strengthening of reinforced concrete beams using various techniques," Construction and Building Materials, vol. 20, no. 6, pp. 366-373, 2006.

[20] M. Shamsai, H. Sezen, and A. Khaloo, "Behavior of reinforced concrete beams post-tensioned in the critical shear region," Engineering Structures, vol. 29, no. 7, pp. 1465-1474, 2007.

[21] A. Demir, E. Ercan, and D. D. Demir, "Strengthening of reinforced concrete beams using external steel members," Steel and Composite Structures, vol. 27, no. 4, pp. 453-464, 2018.

[22] X. Shao, R. Pan, H. Zhao, and Z. Shao, "Prestress loss of a new vertical prestressing anchorage system on concrete box-girder 
webs," Journal of Bridge Engineering, vol. 19, no. 2, pp. 210219, 2014.

[23] X. W. Xue, Study on the control of mid-span deflection and crack of long-span prestressed concrete beam bridges, Ph.D. thesis, Jinan University, Guangzhou, China, 2013.

[24] D. H. Dan, P. F. Jia, and G. Q. Li, "Experimental study on mechanical and sensing properties of smart composite prestressed tendon," Materials, vol. 11, no. 11, p. 2087, 2018.

[25] X. G. Zhong, "Statistical study of the inclination errors of vertically prestressed anchor plates of concrete box beams," China Civil Engineering Journal, vol. 43, no. 5, 2010.

[26] S. K. Li, F. Zhang, and S. C. Li, "Research on the influence of constructing localization of vertical prestress tendons to their prestress loss," Journal of Shandong University, vol. 43, no. 3, pp. 101-105, 2011.

[27] K. C. Zhang, J. Z. Chen, H. Q. Liu, and Y. Zheng, "Research of vertical prestressed losses during construction process of PC continuous box girder bridge," Applied Mechanics and Materials, vol. 351-352, pp. 1142-1145, 2013.

[28] J. Liao, G. R. Ye, and X. Xu, "Analysis of cracks in continual box-girder with prestressed concrete bridge and assessment of reinforcement," China Journal of Highway \& Transport, vol. 17, pp. 62-65, 2004.

[29] X. Zhong and M. Shen, "Influence of non-grouted verticalprestressed-ducts on sectional web cracking of concrete box girder bridges," China Civil Engineering Journal, vol. 41, pp. 60-65, 2008.

[30] F. Cavagnis, M. Fernández Ruiz, and A. Muttoni, "Shear failures in reinforced concrete members without transverse reinforcement: an analysis of the critical shear crack development on the basis of test results," Engineering Structures, vol. 103, pp. 157-173, 2015.

[31] A. Muttoni and R. M. Fernández, "Shear strength of members without transverse reinforcement as function of critical shear crack width," Aci Structural Journal, vol. 105, pp. 163-72, 2008.

[32] F. Cavagnis, M. Fernández Ruiz, and A. Muttoni, "A mechanical model for failures in shear of members without transverse reinforcement based on development of a critical shear crack," Engineering Structures, vol. 157, pp. 300-315, 2018. 


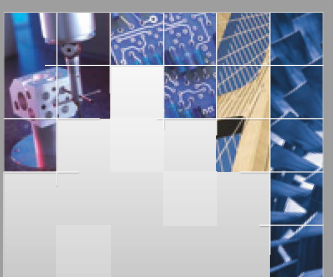

\section{Enfincering}
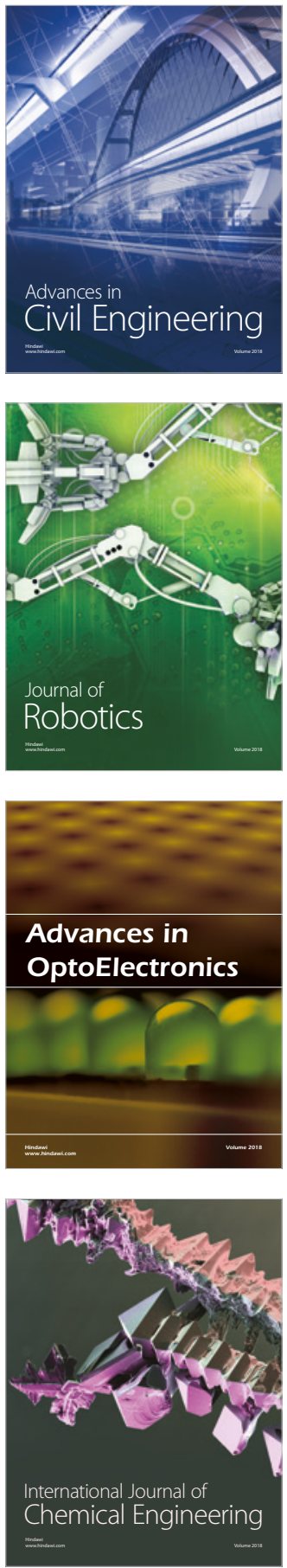

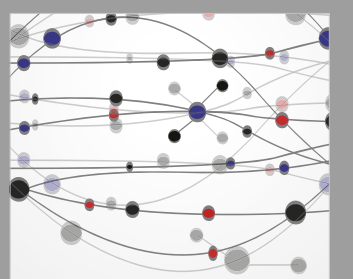

\section{Rotating \\ Machinery}

The Scientific World Journal

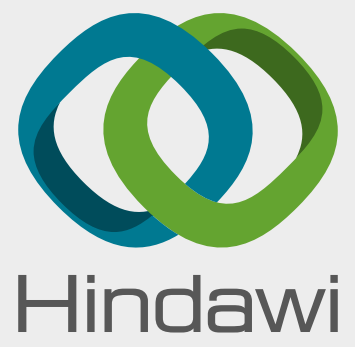

Submit your manuscripts at

www.hindawi.com
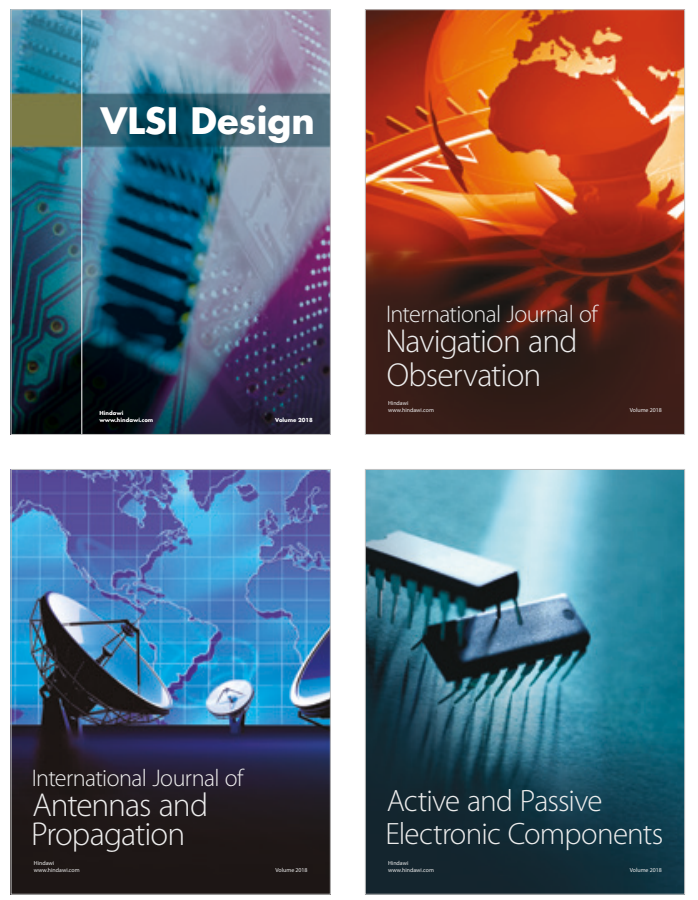
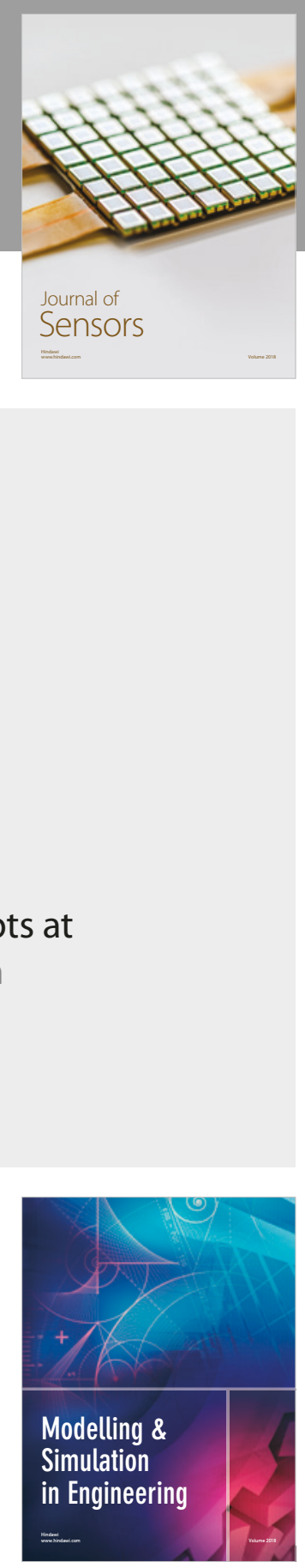

\section{Advances \\ Multimedia}
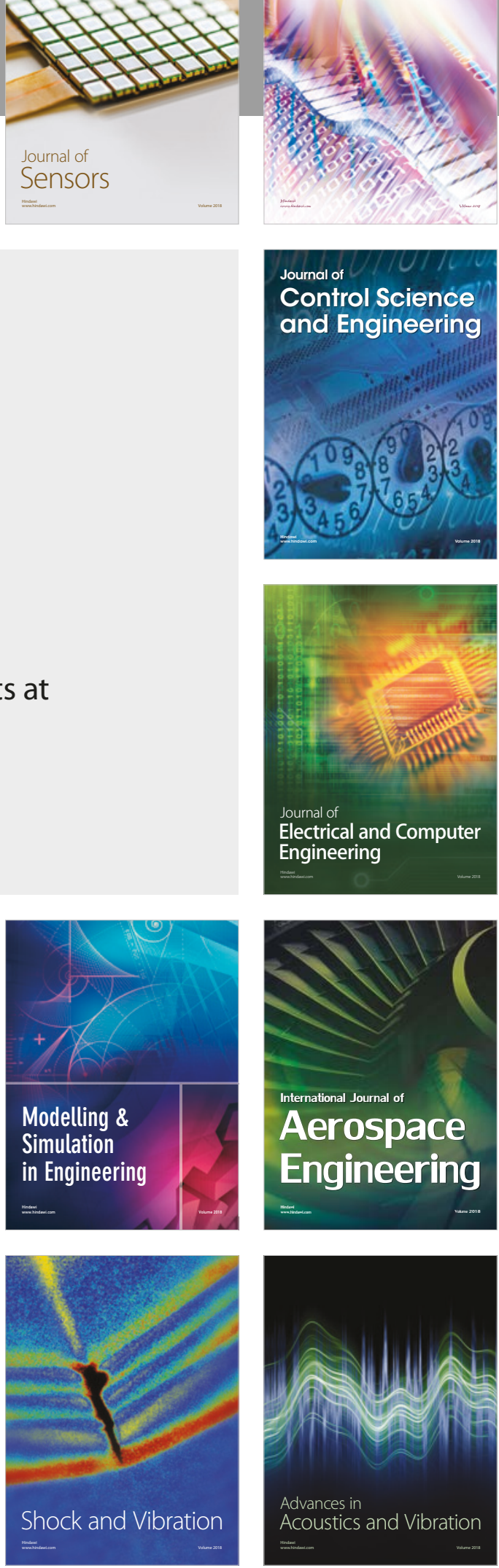